\title{
Is Sprawling Residential Behavior Influenced by Climate?
}

\author{
Cyrus Grout, Jean Cavailhès, Cécile Détang-Dessendre, \\ and Alban Thomas
}

\begin{abstract}
This paper addresses the question of a causal link between climate and urban sprawl by focusing on the role local climate plays in determining household behavior regarding housing decisions. We consider the hypothesis that under warmer climates, households exhibit "sprawling behavior": they locate in larger plots, farther away from city centers. This hypothesis is tested empirically on household data by controlling for sample selection in simultaneous equations for housing size and distance to city center. We find evidence that such sprawling behavior is related to climate, suggesting that global warming and urban sprawl reinforce each other. (JEL C34, R14)
\end{abstract}

\section{INTRODUCTION}

The primary environmental concerns associated with urban sprawl are excessive consumption of land resources and increased greenhouse gas emissions due to the commutes associated with diffuse and uncoordinated patterns of urban expansion (IPCC 2014). Both of these concerns link urban sprawl to contributions to climate change. Here, we explore a different link: the relationship between climate and the spatial organization of cities, specifically the effect of climate on urban sprawl. If this effect is demonstrated, a second conclusion emerges, namely, that global warming and urban sprawl, which have emerged as two major environmental concerns, are linked in a vicious circle: the latter contributes to the former, and vice versa.

The primary causes of urban sprawl have been well identified in the economic literature. Rising incomes and auto-driven changes in transportation costs are the fundamental driv-

Land Economics • May 2016 • 92 (2): 203-219 ISSN 0023-7639; E-ISSN 1543-8325

(C) 2016 by the Board of Regents of the

University of Wisconsin System ers of sprawling development (Glaeser and Kahn 2004), and the movement of the middle class to the suburbs has been in part a response to fiscal and social problems in urban centers (Nechyba and Walsh 2004). The attraction of environmental amenities found outside of urban areas has also been found to play a role (Roe, Irwin, and Morrow-Jones 2004; Wu 2006; Irwin, Jeanty, and Partridge 2014).

Environmental concerns associated with urban sprawl include its indirect effects on climate change. A number of studies have analyzed the links between sprawl-induced increases in energy use and consumption of green space, and increases in the concentration of greenhouse gases in the atmosphere (e.g., Bart 2010). The well-known figure by Newman and Kenworthy shows a strong relationship between urban density and energy consumption: slack North American cities are more energy intensive than dense Asian cities (Newman and Kenworthy 1999). But what about the reverse link, namely, the effect of climate on the extent of urban sprawl? To our knowledge, only a few papers account for that relationship and do so only incidentally. For example, Burchfield et al. (2006) and Patacchini and Zenou (2009) find that climate is a significant determinant of the extent of urban sprawl. However, the contribution of climate to urban sprawl is not a focus of these studies; rather, they use regional climate as a control

The authors are, respectively, consulting researcher, Center for Education Data and Research, University of Washington-Bothell, Seattle; research director, INRA, Université Bourgogne Franche-Comté, Dijon, France; senior researcher, INRA, Université Bourgogne Franche-Comté, Dijon, France; and senior researcher, INRA, Toulouse School of Economics, Toulouse, France. 
variable in cross-sectional analyses of urban area-level measures of sprawl. Moreover, the potential link between a warming climate and urban sprawl is widely ignored. Cavailhès et al. (2014) are the only authors who use individual data in an empirical model with microeconomic foundations. On the whole, how urban growth patterns may respond to a changing climate is generally left unstudied (Irwin et al. 2009).

In this paper, we focus on the role local climate characteristics play in determining some aspects of urban sprawl. We empirically test if, in milder climates in France, households' preferences for large plots are stronger and if easier driving conditions lead to residential locations more distant from city centers. Our analysis uses data from weather stations on temperature and days of precipitation, and detailed household-level survey data to account for differences in households' characteristics. France, which has a temperate climate, does not experience extreme climatic variation. Nevertheless, due to the variable influences exerted by the Mediterranean, Atlantic Ocean, and a varied terrain, substantial variation in temperature and precipitation is observed across the country, providing an appropriate setting in which to study the question of interest.

To test the relationship between climate and urban sprawl, we model residential location choices represented by distance to city center and residential lot size, as a function of household and urban characteristics and local climate. The latter is expected to influence distance to city center, as well as preferences for outdoor space, and therefore lot size. As characterized by Smith, Rosen, and Fallis (1988), every household is assumed to belong to a submarket that is differentiated by location, dwelling type, type of tenure (i.e., owner or renter), age, quality, and financing. Our analysis considers the behavior of a particular submarket that plays a prominent role in defining patterns of urban sprawl: owner-occupants outside of the central cities of urban areas. This sample restriction may introduce sample selection bias if the distribution of the selected sample is not random. Therefore, we adopt an estimation strategy to simultaneously predict the distance to the city center and the residential plot's size using a simultaneousequation procedure suggested by Gouriéroux (2000). ${ }^{1}$ We find evidence that households' residential decisions are related to climate conditions, suggesting that under a warmer climate, households' preferences for sprawling forms of development will increase.

\section{IS CLIMATE A DETERMINANT OF URBAN SPRAWL?}

A number of papers advance a synthetic analysis of the causes of sprawl. ${ }^{2}$ According to Glaeser and Kahn (2004) (among others), the automobile is the primary driver of urban sprawl. Brueckner (2000) underlines the role of improved transportation infrastructure in lowering commuting costs, as well as increasing incomes, in driving urban growth. In an analysis of urban sprawl in Europe, the European Environment Agency synthesizes the determinants of sprawl, connecting it with new lifestyles outside the inner city (European Commission 2006). The report also discusses the role of improved transportation links and personal mobility in allowing individuals to live in more and more distant locations, and identifies several determinants of urban sprawl: for example, micro- and macro-socioeconomic trends, land prices, individual preferences, demographic trends, and land use planning policies.

Climate is a well-known driver of human behavior, and the literature on its effects on population migrations has a long history (e.g., Graves 1976, 1980; Graves and Linneman 1979). Cheshire and Magrini (2006) have shown its effect on the growth of urban populations in the south of each European country (the southern borders blocking migration beyond). However, the relationship between climate and urban sprawl is studied by very few authors. As previously stated, Burchfield et al. (2006) and Patacchini and Zenou (2009) show

\footnotetext{
${ }^{1}$ This specification controls for two sources of bias: (1) sample selection bias resulting from plot size being observed only when a household locates in a house (as opposed to an apartment), and (2) bias resulting from our measure of distance being censored at zero for households living within a central municipality (a limitation of our data).

2 See Glaeser and Kahn (2004), Brueckner (2000), and Irwin et al. (2009) for literature reviews.
} 
that urban sprawl is greater where the weather is warmer, but do not investigate climate as a driver of sprawl.

Cavailhès et al. (2014) build an urban economic model in which the residential location choice of the household depends on the climate in three ways: (1) the household directly consumes a climatic amenity (as in Roback 1982), (2) household preferences depend on climate such that demand for an outdoor way of life is greater where the climate is warm, and (3) travel conditions are influenced by climate (higher transportation costs when winter weather is cold and damp). In that theoretical model, warm climate fosters urban sprawl. Two assumptions underlie the formulation of the empirical model:

- Where the climate is milder, people locate farther into the countryside for two reasons. First, commuting is easier than in a cold region, where winter driving is difficult due to, for example, fog, glare, snow, and ice. Second, in regions where the summer is warm, locating outside of city centers is a means of avoiding the heat-island effects of cities.

- Where the climate is milder, people live on larger plots, because they spend more time using a larger residential lot ("pursuing an outdoor lifestyle"); for example, it may provide space for a swimming pool, a barbecue, a garden, or an outdoor game area.

To test these assumptions we model households' residential behavior in terms of their choices of lot size and distance to city center. Next, we define urban sprawl and our measure of sprawling residential behavior.

\section{DEFINITION AND MEASURE OF URBAN SPRAWL}

Although "urban sprawl" is a well-recognized term, it lacks a definition that is precise and generally accepted. Brueckner (2001) defines urban sprawl as the "spatial growth of cities that is excessive to what is socially desirable," reflecting the negative connotations that typically accompany discussions of urban sprawl. Others are more circumspect about its desirability, finding that it has increased households' well-being due to the higher household consumption of land and housing it has enabled (Glaeser and Kahn 2004; Nechyba and Walsh 2004). While the multifaceted nature of urban sprawl does not lend itself to any particular quantitative measure, economic analyses of sprawl tend to focus on the dimensions of density and centrality. ${ }^{3}$ In general, these studies measure the degree of sprawl in terms of the distribution of jobs and/ or residential population relative to a metropolitan city center, and defined by density gradients (e.g., Anas and Arnott 1997; Glaeser, Kahn, and Chu 2001; Glaeser and Kahn 2004; Mieszkowski and Mills 1993). ${ }^{4}$

From a microeconomic perspective, sprawl is clearly an outcome of residential behavior. But the sprawling behavior of households choosing their residential locations remains a black box in economic studies. At best, statistical correlations are established between the characteristics of urban area populations and variables measuring geographic settlement patterns. In the present paper, we open the black box by empirically analyzing residential choices using individual household data rather than urban area-level metrics. The metrics we focus on in the present paper are residential lot size and commuting distance. The choice of residential lot size and commuting distance as variables to represent urban sprawl is relatively novel to the economic literature. In empirical analyses, economists have tended to use urban area-level statistics rather than household-level choices as dependent variables.

Table 1 reports descriptive statistics on climate (temperature) and housing characteristics, obtained from the housing survey conducted in 2006 by the French National Institute of Statistics and Economic Studies (INSEE 2006a). Regarding the consumption of residential goods, Table 1 shows that the

\footnotetext{
${ }^{3}$ Geographers also tend to consider the dimensions of fragmentation (i.e., the spatial organization of density) and the level of accessibility to jobs, shopping areas, and transportation (Galster et al. 2001).

${ }^{4} \mathrm{~A}$ few more recent studies have measured urban sprawl in terms of the degree of scatteredness of urban development (Burchfield et al. 2006), using urban area-level indicators related to built-up areas, continuity of residential areas, and population density (Kasanko et al. 2006), and by the variation over time of urban land use and population density (Patacchini and Zenou 2009).
} 
TABLE 1

July Temperature and House Characteristics

\begin{tabular}{lcccc}
\hline \hline July Temperature & Swimming Pool & Terrace Size $\left(\mathrm{m}^{2}\right)$ & Plot Size $\left(\mathrm{m}^{2}\right)$ & Floor Space/Lot Size \\
\hline Below median & $1.30 \%$ & 8.5 & 1,128 & 0.34 \\
Above median & $6.40 \%$ & 10.2 & 1,453 & 0.26 \\
\hline
\end{tabular}

Source: 2006 housing survey (INSEE 2006a), sample individual household, excluding Paris metropolitan area.

TABLE 2

Temperature in January and Commuting Time

\begin{tabular}{lccc}
\hline \hline & \multicolumn{3}{c}{ Commuting Time (Individual Declaration/Expert Calculation) } \\
\cline { 2 - 4 } January Temperature & All Households & Executives & Blue Collar Workers \\
\hline Below median & 0.978 & 0.977 & 0.977 \\
Above median & 0.933 & 0.915 & 0.930 \\
\hline
\end{tabular}

Source: 2006 housing survey (INSEE 2006a), sample individual household, excluding Paris metropolitan area, and authors' computations.

proportion of homes with swimming pools increases with temperature in July. Similarly, yard size increases by $20 \%$ (from 8.5 to 10.2 $\mathrm{m}^{2}$ ) for the houses in climates that are warmer than average. The overall lot sizes of these homes is almost $36.4 \%$ higher in the warmer half of the country (about 1,500 $\mathrm{m}^{3}$ vs. 1,100 $\mathrm{m}^{3}$ ), and the ratio of floor area to the area of the plot is about one-third in the colder half of the country and about one-quarter in the warmer half. These patterns illustrate the outdoor way of life enjoyed in French regions with warmer climate..$^{5}$

The direct comparison of commuting times in different climates requires controlling for both regional variation in urban structure and road networks, and we present descriptive statistics from two data sources. First, the 2006 housing survey by the INSEE provides travel time reported by the household (denoted "reported time"). To estimate her reported commuting time, the worker takes into account all the characteristics necessary to optimize it: the road network (motorways, windings, etc.) and urban structure (congestion, etc.), as well

\footnotetext{
5 A more general comparison of lifestyle and welfare according to climate is beyond the scope of this paper and would require a more advanced econometric analysis. In cold regions, living area is slightly larger $(+1 \%)$, the price of housing is smaller (Cavailhès et al. 2014), and so forth. Other differences may occur in the way of life, and it is impossible to make a balance.
}

as climate. As the residential and work places are known in this housing survey, the second source is the calculation of commuting time for the same journey using the algorithms in Odomatrix, a numerical tool used to compute the shortest route between two places, and the corresponding time required to traverse that route (denoted "computed time"). 6 This second source controls for geographic and traffic conditions, but it does not take into account the effect of climate on commuting time. We calculate the ratio between the reported time and the computed time for 6,697 observations where the head of household goes to work in a private motor vehicle. For the whole country, the reported time is on average $4.0 \%$ lower than the computed time. Table 2 shows that among households located in areas where the temperature in January is below the median, the times reported by households are on average $2.2 \%$ lower than computed times. Among households where the temperature in January is above the median, the reported times are $6.7 \%$ lower than computed times. In other words, when the winter weather is

6 The Odomatrix tool (INRA-CESAER) uses the road network "route500(r)" from the Institut Géographique National. It takes into account the geographic surroundings (altitudes, slopes, agglomerations, countryside, etc.) and traffic conditions (off-peak and peak hours). The tool chooses the itinerary that minimizes the transport time (Hilal 2010). 
colder, the worker takes longer to get to work because she drives slower and/or provides a margin of safety because of weather. Our hypothesis is that this difference is due to more difficult driving conditions in cold and rainy regions in the winter.

While the difference between the computed and reported times is roughly the same whether the head of household is an executive or blue collar worker where January is cold $(2.4 \%)$, the difference is more pronounced for executives $(9.3 \%)$ than for blue collar workers $(7.5 \%)$ in the warmer parts of the country. This suggests that the commute times of the executives are more strongly influenced by cold winters. A similar calculation for lot size shows that in comparison to regions with below-average July temperatures, lot size increases more for blue collar workers $(35 \%)$ than for executives $(21 \%)$. These descriptive statistics illustrate one of the advantages of working on individual data. It allows one to compare the behavior of households according to socioprofessional status, as we have just done for commuting time. Of course, a wellspecified econometric model has to be designed to test for such relationships.

\section{EMPIRICAL STRATEGY}

Following Cavailhès et al. (2014), we assume that the size of the residential good and the distance from the city center (or leisure) are simultaneously chosen by each household, leading to endogenous variables in the model. Therefore, we characterize a household's choice as the simultaneous equations in system [1]. The introduction of covariates is to control for (part of the) observed heterogeneity in households and urban areas:

$\left\{\begin{array}{l}S=f\left(D, w, \boldsymbol{\alpha}_{1}, \mathbf{C}_{1}, \mathbf{Y}_{1}\right)+\varepsilon_{1}, \\ D=g\left(S, w, \boldsymbol{\alpha}_{2}, \mathbf{C}_{2}, \mathbf{Y}_{2}\right)+\varepsilon_{2}\end{array}\right.$

where $S$ is the size of the residential plot, $D$ is distance to the center of the urban area, $w$ is the income of the household, $\boldsymbol{\alpha}_{1}$ and $\boldsymbol{\alpha}_{2}$ are vectors of household characteristics, $\mathbf{C}_{1}$ and $\mathbf{C}_{2}$ are vectors of climate variables, and $\mathbf{Y}_{1}$ and $\mathbf{Y}_{2}$ are vectors of local variables specific to urban areas.
We distinguish between two spatial levels used to define the local variables in $Y$ : the urban area in which the residence is located and the local community with which the residence is associated. The French urban area definition is similar to that of metropolitan statistical areas in the United States, but the population thresholds are lower. ${ }^{7}$ We have associated rural communities, which are beyond the urban area border, to their nearest urban area. Therefore, all location decisions (in urban as well as rural destinations) are considered. The local-community grid of France comprises 35,565 communes (similar to townships or municipalities in the United States) that we associate with 354 urban areas.

The household socioeconomic data are from housing surveys conducted by INSEE in 1984, 1988, 1992, 1996, 2002, and 2006 (INSEE 1988，1992，1996，2002，2006a), which are stacked and merged with spatial data (including periodic INSEE censuses and the delineation of urban areas) and climatic data. ${ }^{8}$ Table 3 presents definitions of the household, local, urban area, and climate variables used in our sample.

\section{Model Specification and Estimation Methods}

We assume each household has freely chosen its location and the characteristics of the parcel (in particular, its size) in a competitive market without imperfections or failures. The competition between numerous development companies operating across the entire country makes such a competitive market assumption plausible. ${ }^{9}$ Residential lot sizes may be different from those defined by the market equilibrium, due to zoning restrictions. Neverthe-

\footnotetext{
${ }^{7}$ In the French statistical definition created by INSEE, an aire urbaine (urban area) consists of a unité urbaine (central city and suburbs defined by the continuity of the builtup area and the hosting of at least 5,000 jobs) and a periurban belt (municipalities with discontinuous built-up land where at least $40 \%$ of active residents commute to work outside the local community, but within the urban area).

${ }^{8}$ We thank INSEE for providing us with the computing and technical facilities required for econometric modeling on a remote secured data server.

${ }^{9}$ Average land price (calculated at the urban-area level) helps control for local market variations.
} 
TABLE 3

Definition of Variables and Statistical Sources

\begin{tabular}{ll}
\hline \hline Variable & \multicolumn{1}{c}{ Source $^{\mathrm{a}}$} \\
\hline Endogenous Variables & \\
Lot size & $\begin{array}{l}\text { Housing survey } \\
\text { Distance }\end{array}$ \\
\end{tabular}

\section{Household Characteristics}

$\ln$ (Income)

Housing survey

Age

Children

Socioprofessional status

Housing survey

French national census

\section{Urban Area and Land Market Characteristics}

Average land price

Average price index

Urban area population

Urban center/urban area

\section{Local Characteristics}

Forest rate

$\ln$ (Local income)

Coastal community

Climate Variables

$\ln$ (Temperature July)

$\ln$ (Temperature January)

$\ln$ (Rainy days January)

\author{
Solicitors' data \\ Conseil Général de \\ l'Environnement et du \\ développement durable \\ French national census
}

French national census

Corine Land Cover database French national census

Institut Géographique National Méteo-France and specific
intrapolation $^{c}$
Size of the lot for houses

Driving time in minutes to the closest urban center via the road network; defined at the community level (the smallest level of French administrative delimitation), this distance equals zero if a household is located in the central local community of an urban area

Total household income (in log), deflated by the GDP index (year 2006).

Age of the head of household

Dummy variable for the presence of children (yes/no)

Executive, Blue collar worker, Office worker, and Other are dummy variables indicating the occupation of the head of household; Intermédiaire ${ }^{\mathrm{b}}$ being the reference

Average land price in the urban area

Annual housing price index of the year of dwelling purchase (national trends in the housing market)

Dummy variables indicating that the size of the household's aire urbaine is in one of the following classes: $<50,000$ inhabitants, 50,000 to 100,000 inhabitants, 100,000 to 200,000 inhabitants, 200,000 to 500,000 inhabitants, and $>500,000$ inhabitants

Share of the surface of the urban area covered by the urban center

Share of municipality area covered by forest

Average per-capita income of the local community (in $\log )$

Dummy variable indicating that the local community is located on a coastline

Average temperature (in log) over the period 1971-2000 in the household's local community during the month of July (centigrade degrees)

Average temperature (in log) over the period 1971-2000 in the household's local community during the month of January (centigrade degrees)

Average number of days of rain (in log) over the period the 1971-2000 in the household's local community during the month of January

\footnotetext{
a Housing survey: ISEE 2006a; French national census: INSEE 2006b; Solicitors' data: INSEE 2015; Conseil Général de l'Environnement et du développement durable: CGEDD 2015; Corine Land Cover database: European Environment Agency 2015; Institut Géographique National: www.ign.fr; and Méteo-France and specific intrapolation: Joly 2011.

$\mathrm{b}$ There is no satisfactory translation to English for this category, which includes intermediate professions in education, health, public service, and corporate administration, as well as technicians, foremen, and supervisors.

c These data are recorded by a network of weather stations, and interpolation is used to reconstruct a spatial continuum of weather data using a GIS (Joly et al. 2011). Regressions between temperature/rainfall and explanatory variables suggested by climatology (altitude, land cover, orientation, etc.) were estimated, followed by kriging of residuals from the regressions. As the models and parameters estimated are not identical over an area of the size of France, interpolation is done for small polygons including the 30 closest stations. The predicted values are computed for each French municipality.
} 
less, $66 \%$ of French municipalities did not have any zoning as of 1988, and fewer than $50 \%$ did as of 2003 (Lecat 2006). Moreover, where zoning restrictions exist, the effect on plot size is likely to be limited. As demonstrated by a large survey of the literature by Lecat (2006), zoned plot sizes tend to follow, more or less, the market.

We assume that it is the households who move that drive the size and the location of new development. In other words, households are price takers because they are small agents, but they are quantity makers because the highest bidder in the market can choose her desired residential plot size. It is among these households that we are able to observe a residential location decision that reflects preferences for proximity and indoor/outdoor space.

While our research question could in principle be addressed by analyzing all residential development in France, it would be inappropriate to apply our model to the entire housing market for a number of reasons. First, the housing market consists of newly constructed and older dwellings. The locations of older buildings depend on outdated circumstances, whether in terms of transportation technology (particularly the widespread adoption of the automobile) or historical disruptions (e.g., rebuilding in inner cities after the damages of the Second World War in the cold north, or accommodating repatriation from Algeria in 1962 in exurban areas of the warm south). The period of time since 1974 is relatively stable along both of these dimensions. Therefore, we focus on contemporaneous location mechanisms by selecting developments constructed since $1974 .{ }^{10}$ Second, we consider that renters and owner-occupants belong to separate residential markets, with different preference structures and budget constraints, and restrict our analysis to the behavior of owner-occupants. Third, we limit our analysis to households that have recently moved (in relation to the household survey date). Indeed, the survey gives contemporaneous information on

\footnotetext{
${ }^{10}$ As a robustness check, we estimate our model on all housing stock, regardless of date of construction. The results are very comparable to those obtained for new developments; in particular, the impact of climate follows the same profile. Results are available from the authors upon request.
}

households. If we consider all households regardless of moving date, the observed characteristics of many households will be different than they were when the location decision was undertaken. Fourth, we exclude farmers and retired people from consideration because they do not have the same relationship to the central cities of urban areas (in terms of proximity to job centers) as other households. Finally, we exclude the urban area of Paris, the scale of which is very different from every other urban area (it contains approximately one-fifth of the French population) and would be difficult to accommodate under a single econometric model. Under these restrictions, the surveyed population of interest utilized in our analysis consists of 16,947 households.

\section{The Selection Problem}

The selection process associated with defining the population of interest should not introduce selection bias, as all criteria are intended to delineate a specific market. However, we encounter two major econometric issues related to the definition of the two dependent variables, residential plot size $(S)$ and distance $(D)$. The first issue is that residential plot size is equal to zero for a significant number of dwellings in the population of interest. These dwellings are generally apartments, and the interpretation of $S=0$ is not the same for a house and an apartment. Moreover, some unobserved factors may influence the household's choice between flat and house that are also related to the selection of lot size and distance. As such, we introduce a selection equation explaining a household's choice between a house and an apartment, and then compute a selection correction term to control for the potential bias. The dependent variable in this equation $(H)$ equals 1 if the household lives in a house, and 0 otherwise. The second issue arises from the measurement of distance. Due to the software computing distance as travel time in minutes from the center of the household's commune to the center of the urban area, it censored at zero for all households located in the community that is the central city of its aire urbaine (see the definition of distance in Table 3). 
Among the 16,947 observations in the population of interest, 1,775 (10.4\%) are households living in apartments $(H=0)$ and $2,718(16.0 \%)$ are in the central municipalities of their respective urban areas. A total of $13,377(78.9 \%)$ households reside in houses $(H=1)$ outside of urban area city centers.

Standard econometric procedures exist to deal jointly with sample selection and censored-observation mechanisms. In a singleequation setting, parametric or semiparametric procedures are available to correct for endogenous selection under a variety of model specifications and with weak assumptions on the distribution of errors. However, when multiple sources of selection are present, estimation techniques entail more involved numerical methods such as simulationbased integration, or require simplifying restrictions such as joint normality of error terms and/or independence of selection equations (see, e.g., Yen, Lin, and Smallwood 2003; Lacroix and Thomas 2011).

The fact that our model consists of simultaneous equations with selection requires an estimation strategy to deal with selection bias, censored observations, and simultaneity bias (endogeneity of some explanatory variables). One possibility is to estimate the model in reduced form while accounting for selection and the censored dependent variable, and solve for the structural parameters. However, this indirect least squares approach requires the model to be exactly identified (Gouriéroux 2000), which reduces the number of exogenous regressors that can inform the size and distance equations. Another possibility is to construct the likelihood functions based on the normality assumption and perform maximum-likelihood estimation, which is likely to be cumbersome given the multiple sources of selection and the large number of observations. We adopt a simpler approach that corrects for the selection and censoring bias in a multistep procedure based only on probit and three-stage least squares (3SLS) estimators.

\section{Estimation Strategy}

Given equation [1], the underlying econometric structural model can be written as a system of equations: $\left\{\begin{array}{l}\ln S=\mathbf{X}_{1} \beta_{1}+\ln D \gamma_{1}+\varepsilon_{1} \\ \ln D=\mathbf{X}_{2} \beta_{2}+\ln S \gamma_{2}+\varepsilon_{2}\end{array}\right.$,

where $S$ is the size of the residential plot, $D$ is the driving distance in minutes to the central city, and $\varepsilon_{1}$ and $\varepsilon_{2}$ are random terms. $\mathbf{X}_{1}$ and $\mathbf{X}_{2}$ are two vectors of observed explanatory variables. The corresponding reduced-form model is

$\left\{\begin{array}{l}\ln S=\mathbf{X}_{1} \pi_{11}+\mathbf{X}_{2} \pi_{12}+u_{1} \\ \ln D=\mathbf{X}_{1} \pi_{21}+\mathbf{X}_{2} \pi_{22}+u_{2}\end{array}\right.$,

where $\left(u_{1}, u_{2}\right)$ are assumed jointly normal $N\left(0_{2}, \Sigma\right)$, with $\mathrm{O}_{2}$ and $\Sigma$, respectively, indicating a rank-2 vector of zeros and a rank-2 variance-covariance matrix.

As mentioned above, we need to control for selection bias affecting both equations, and censored observations (affecting distance $D$ only). Consider the selection of the type of housing first. In terms of observed variables, the following condition applies to the first equation of the reduced form:

$\left\{\begin{array}{l}H^{*}=\mathbf{X}_{3} \beta_{3}+\varepsilon_{3} \\ H=1 \text { if } H^{*}>0 ; 0 \text { otherwise }\end{array}\right.$

where $H^{*}$ is a latent variable representing the willingness to choose a house (as opposed to an apartment), and $\mathbf{X}_{3}$ is a vector of observed explanatory variables. Because $H^{*}$ is unobserved, we assume without loss of generality that it is positive when the observed choice is $H=1$.

The conditional expectation of plot size $(S)$ corresponding to the subsample of observations in houses $(H=1)$ is

$$
\begin{aligned}
& \mathrm{E}\left(\ln S \mid \varepsilon_{3}>-\mathbf{X}_{3} \beta_{3}\right)= \\
& \quad \mathbf{X}_{1} \pi_{11}+\mathbf{X}_{2} \pi_{12}+\mathrm{E}\left(u_{1} \mid \varepsilon_{3}>-\mathbf{X}_{3} \beta_{3}\right) .
\end{aligned}
$$

The treatment of the second equation is more involved, as we have to deal with the selection condition above, as well as censored observations on distance:

$\left\{\begin{array}{l}\ln D=\mathbf{X}_{1} \pi_{21}+\mathbf{X}_{2} \pi_{22}+u_{2}, \\ H^{*}=\mathbf{X}_{3} \beta_{3}+\varepsilon_{3}, \\ H=1 \text { if } H^{*}>0,0 \text { otherwise, } \\ \ln D=\ln D^{*} \text { if } D^{*}>0 \text { and } H^{*}>0 .\end{array}\right.$ 
Within a linear regression framework such as 3SLS, we need to evaluate the following conditional expectation:

$$
\begin{gathered}
\mathrm{E}\left(\ln D \mid{ }_{\varepsilon} 3>-\mathbf{X}_{3} \beta_{3}, u_{2}>-\mathbf{X}_{1} \pi_{21}-\mathbf{X}_{2} \pi_{22}\right)= \\
\quad \mathbf{X}_{1} \pi_{21}+\mathbf{X}_{2} \pi_{22}+\mathrm{E}\left(u_{2} \mid \varepsilon_{3}>-\mathbf{X}_{3} \beta_{3}, u_{2}>\right. \\
\left.-\mathbf{X}_{1} \pi_{21}-\mathbf{X}_{2} \pi_{22}\right)
\end{gathered}
$$

where $\left(u_{1}, u_{2}, \varepsilon_{3}\right)$ are jointly normal $N\left(0_{3}, \Sigma\right)$.

The two sources of bias (sample selection and censored observations) are controlled for as follows. In a first step, we estimate a bivariate probit model on $H=1$ (explained by the covariates in $\mathbf{X}_{3}$ ) and $D^{*}>0$ (explained by $\mathbf{X}_{1}$ and $\mathbf{X}_{2}$ ). We use three variables as instruments in the house equation: a variable indicating the household undertook energy-conserving renovations; a variable indicating the home loan did not cover $100 \%$ of the investment; and a variable indicating the household received social help to pay the loan. We find no correlation between these variables and the size of the lot or distance to the city center. As expected, the bivariate probit (House = $1, D^{*}>0$ ) exhibits a strong correlation: the decisions to live in a house and to locate outside of the central city of the urban area are positively correlated $(\rho=0.62$, with $p$-value 0.02 ).

In a second step, we build the bivariate selection term as follows: ${ }^{11}$

$$
\begin{gathered}
\mathrm{E}\left(u_{2} \mid \varepsilon_{3}>-\mathbf{X}_{3} \beta_{3}, u_{2}>-\mathbf{X}_{1} \pi_{21}-\mathbf{X}_{2} \pi_{22}\right)= \\
\theta_{1} \lambda_{1}+\theta_{2} \lambda_{2},
\end{gathered}
$$

where

$$
\begin{aligned}
\lambda_{1}= & \phi\left(\mathbf{X}_{3} \beta_{3}\right) \times \Phi\left(Z_{1}^{*}\right) / \Phi_{2}\left(\mathbf{X}_{3} \beta_{3}, \mathbf{X}_{1} \pi_{21}+\mathbf{X}_{2} \pi_{22}, \rho\right), \\
\lambda_{2}= & \phi\left(\mathbf{X}_{1} \pi_{21}+\mathbf{X}_{2} \pi_{22}\right) \times \\
& \Phi\left(Z_{2}^{*}\right) / \Phi_{2}\left(\mathbf{X}_{3} \beta_{3}, \mathbf{X}_{1} \pi_{21}+\mathbf{X}_{2} \pi_{22}, \rho\right),
\end{aligned}
$$$$
Z_{1}^{*}=\left[\left(\mathbf{X}_{1} \pi_{21}+\mathbf{X}_{2} \pi_{22}\right)-\rho\left(\mathbf{X}_{3} \beta_{3}\right)\right] / \sqrt{\left(1-\rho^{2}\right)},
$$$$
Z_{2}^{*}=\left[\mathbf{X}_{3} \beta_{3}-\rho\left(\mathbf{X}_{1} \pi_{21}+\mathbf{X}_{2} \pi_{22}\right)\right] / \sqrt{\left(1-\rho^{2}\right)} .
$$

Also, $\phi(\cdot)$ and $\Phi(\cdot)$ are, respectively, the density and the cumulative distribution function

\footnotetext{
${ }^{11}$ For details about the derivation of these correction terms, see Ham (1982) and Gouriéroux (2000).
}

of the normal distribution $N(0,1) ; \Phi_{2}(\cdot, \cdot, \cdot$, is the bivariate cumulative distribution function (probability estimated from the bivariate probit); $\rho$ is the correlation coefficient between $\varepsilon_{3}$ and $u_{2}$ (obtained from the bivariate probit); and $\theta_{1}$ and $\theta_{2}$ are parameters to be estimated. We then can finalize the estimation of the simultaneous equation model in two steps, by including the inverse Mills ratio and bivariate selection terms (see Ham 1982). Standard errors are estimated using the bootstrap method.

\section{RESULTS}

Results of the last estimation step are presented in Table 4. Lot size and distance are positively linked and simultaneously determined, with larger lot sizes associated with locations more distant from the city center. The inverse Mills ratio is insignificant in the lot size equation: we do not find evidence of a selection process in which people who choose to live in a house have unobserved characteristics that lead them to choose a larger lot size. In the distance equation, $\lambda_{1}$ and $\lambda_{2}$ are positive and significant, controlling for the fact that people who choose to live outside the city center have unobserved characteristics associated with a preference for houses (vs. apartments) and more distant locations. Due to the selection treatments, estimated parameters cannot be interpreted as elasticities. The computation of elasticities is straightforward in the case of the lot size equation, but quite cumbersome in the case of the distance equation, as the parameter values $\lambda_{1}$ and $\lambda_{2}$ must be derived. Therefore, elasticities are computed (over the whole sample) only for the climate variables. ${ }^{12}$

\section{Control Variables}

Most of the variables controlling for household characteristics have the expected sign. Wealthier households locate on larger plots and closer to the center of the urban area, which is consistent with the behavior of

\footnotetext{
12 Details of the computation are available from the authors upon request.
} 
TABLE 4

Structural Equation Estimates

\begin{tabular}{|c|c|c|}
\hline & Estimate & Bootstrapped Std. Err. \\
\hline \multicolumn{3}{|l|}{ Lot Size Equation } \\
\hline $\ln ($ Distance $)$ & 0.463 & 0.141 \\
\hline $\ln ($ Income $)$ & 0.266 & 0.025 \\
\hline Age & 0.002 & 0.001 \\
\hline Single (yes) & 0.026 & 0.090 \\
\hline Couple, no children (yes) & -0.026 & 0.029 \\
\hline Children & Reference & Reference \\
\hline Blue collar worker & -0.037 & 0.018 \\
\hline Office worker & -0.060 & 0.022 \\
\hline Intermédiaire worker & Reference & Reference \\
\hline Executive & 0.036 & 0.021 \\
\hline Self-employed & 0.098 & 0.028 \\
\hline Mean land price & -0.005 & $0.30 \mathrm{E} 3$ \\
\hline Land price trend & -0.170 & 0.065 \\
\hline Urban area population $<50,000$ & Reference & Reference \\
\hline Urban area population 50,000 to 100,000 & -0.056 & 0.029 \\
\hline Urban area population 100,000 to 200,000 & -0.160 & 0.021 \\
\hline Urban area population 200,000 to 500,000 & -0.232 & 0.052 \\
\hline Urban area population $>500,000$ & -0.331 & 0.091 \\
\hline $\ln ($ Local income $)$ & 0.157 & 0.022 \\
\hline Coastal community & -0.216 & 0.033 \\
\hline Forest rate & 0.198 & 0.076 \\
\hline Urban pole/urban area & -0.511 & 0.061 \\
\hline $\ln ($ July temperature $)$ & 0.538 & 0.117 \\
\hline Inverse Mills ratio & 0.081 & 0.157 \\
\hline Intercept & 0.135 & 0.650 \\
\hline \multicolumn{3}{|l|}{ Distance Equation } \\
\hline $\ln ($ Lot size $)$ & 0.108 & 0.030 \\
\hline $\ln ($ Income) & -0.137 & 0.015 \\
\hline Age & -0.002 & 0.001 \\
\hline Single (yes) & -0.072 & 0.048 \\
\hline Couple, no children (yes) & -0.001 & 0.017 \\
\hline Children (yes) & Reference & Reference \\
\hline Blue collar worker & 0.066 & 0.014 \\
\hline Office worker & 0.004 & 0.015 \\
\hline Intermédiaire worker & Reference & Reference \\
\hline Executive & -0.026 & 0.016 \\
\hline Self-employed & 0.068 & 0.019 \\
\hline Urban area population $<50,000$ & Reference & Reference \\
\hline Urban area population 50,000 to 100,000 & 0.162 & 0.019 \\
\hline Urban area population 100,000 to 200,000 & 0.170 & 0.020 \\
\hline Urban area population 200,000 to 500,000 & 0.300 & 0.021 \\
\hline Urban area population $>500,000$ & 0.544 & 0.029 \\
\hline Forest rate & 0.577 & 0.040 \\
\hline Urban pole/urban area & -0.210 & 0.039 \\
\hline $\ln ($ January temperature $)$ & 0.069 & 0.010 \\
\hline $\ln$ (January rainy days) & 0.025 & 0.020 \\
\hline Lambda 1 & 0.150 & 0.076 \\
\hline Lambda 2 & 0.179 & 0.063 \\
\hline Intercept & 3.245 & 0.204 \\
\hline
\end{tabular}

Note: System of equations estimated on 13,373 observations. 
French households (see Brueckner, Thisse, and Zenou 1999). A household's socioprofessional status adds supplementary information: as expected, blue collar workers locate on smaller lots and at greater distances than executives and office workers (also consistent with French characteristics). Lot size increases with the age of the head of household, and distance to the city center slightly decreases. In interpreting the results, keep in mind the age distribution in our sample: only $10 \%$ of the heads of household are younger than 30 , and $80 \%$ are between 30 and 53; as a result, the parameter for age is small. Older (i.e., senior) households presumably have income allowing them to locate closer to central cities. The parameters related to household composition are also small. Concerning lot size, income effects seem to dominate, and regarding the distance to the city center, the only differentiation occurs between single and nonsingle households, the former choosing closer locations than the latter. However, household composition appears to play a major role in the first step of the modeling, where we control for the joint choice of house/apartment and urban center/out of the center (see appendix). Indeed, we show that being single or living as a couple without children sharply decreases the probability of living in a house. Being single also increases the probability of living in the urban center.

Variables controlling for regional and local characteristics concerning population of the urban area, urban structure, and housing and land markets behave as expected. To capture the effect of developable land availability on the location decision, we introduce the share of the urban area covered by the central city of the urban area (which is relatively dense). Lot sizes decrease with the populated share of the urban area because greater densities lead to higher land values and smaller plots. Distance to the center of the urban area increases with urban area population: the more populous the urban area, the more distant its edge is from its center.

Regarding land market effects, higher urban area land prices are associated with smaller lot sizes. Lot size is positively linked with the average income of the local community inhabitants, which may be due to min- imum-lot-size zoning regulations designed to exclude poorer households from affluent municipalities. The functioning of the land market is also represented by the share of forest in the local community area and a dummy variable distinguishing coastal municipalities. Lot size and distance increase with forest coverage (a proxy for land availability), and as expected, lot size is smaller in coastal communities, which tend to have very attractive natural amenities and higher prices.

\section{Climate Variables}

The empirical results are consistent with our hypotheses: (1) warmer summer temperatures correspond with larger lot sizes, and (2) lower winter temperatures correspond with location closer to city centers. ${ }^{13}$

To explore these mechanisms further, we calculate the elasticity of lot size and distance in response to a change in climate for a representative household, defined by average values (continuous variables) and reference categories (discrete variables). ${ }^{14}$ A $10 \%$ increase in average July temperature $\left(2^{\circ} \mathrm{C}\right)$ corresponds with a $7.2 \%$ increase in lot size $\left(65 \mathrm{~m}^{2}\right.$ on average). For example, lot sizes in locations with temperatures at the 90th percentile, as in Nice $\left(23^{\circ} \mathrm{C}\right)$, are predicted to be $18 \%$ larger (an increase of approximately $162 \mathrm{~m}^{2}$ on average) than those at the 10 th percentile $\left(18^{\circ} \mathrm{C}\right)$, as in most locations north of the Paris-Strasbourg line of latitude. ${ }^{15}$ A $10 \%$ increase in average temperature in January $\left(0.5^{\circ} \mathrm{C}\right)$ leads to a $0.4 \%$ increase in distance to the urban center. The variation in average January temperatures in France is substantial: the average temperature in January is $3^{\circ} \mathrm{C}$ in Strasbourg (in the northeast of France) and $10^{\circ} \mathrm{C}$ in Nice (in the Mediterranean south of France). The Nice climate applied to Strasbourg leads to a

\footnotetext{
${ }^{13}$ We do not find a significant relationship between the number of rainy days in January and distance.

${ }^{14} \mathrm{Age}=38$; Children = yes; Urban area population $=50,000$ to 100,000 ; Average July temperature $=20^{\circ} \mathrm{C}$; Average January temperature $=5^{\circ} \mathrm{C}$; Rainy January days $=11$. Formulas are available from the authors upon request. Standard errors are bootstrapped.

${ }^{15}$ Applying the correction for selection to the parameter on average July temperature in the lot size equations leads to a slight increase of the elasticity.
} 
TABLE 5

Climate Variable Parameters on Blue Collar and Executive Subsamples

\begin{tabular}{lccccc}
\hline \hline & $\begin{array}{c}\text { July Temperature } \\
\text { in Lot Size } \\
\text { Equation }\end{array}$ & $\begin{array}{c}\text { January } \\
\text { Temperature in } \\
\text { Distance Equation }\end{array}$ & $\begin{array}{c}\text { January Rainy } \\
\text { Days in Distance } \\
\text { Equation }\end{array}$ & $\begin{array}{c}\text { Distance } \\
\text { (on Lot Size) }\end{array}$ & $\begin{array}{c}\text { Lot Size } \\
\text { (on Distance) }\end{array}$ \\
\hline Blue collar workers & $0.589(0.194)$ & $0.049(0.017)$ & $0.163(0.471)$ & $0.939(0.309)$ & $0.041(0.025)$ \\
Executives & $0.677(0.308)$ & $0.117(0.028)$ & $-0.091(0.050)$ & $0.273(0.150)$ & $0.256(0.083)$ \\
\hline
\end{tabular}

Note: Bootstrapped standard errors are in parentheses.

$13.2 \%$ increase in distance to the city center for our representative household (a bit less than 3 minutes at the median distance of 21 minutes). The insignificant effect of precipitation may be due to the small variation across the French territory in January. Indeed, 80\% of localities record between 9 and 13 rainy days in January, and more than $40 \%$ of the local communities record approximately 12 days.

An advantage of using household-level data is that it allows predictions according to the individual characteristics of the households. Many possibilities may be explored and may be extensions for future work: for example, examination of younger versus older households, or single households versus families with children. To illustrate these possibilities we estimate the system of equations for two specific social categories: households with a blue collar worker as head-of-household and those with an executive head-ofhousehold (see Table 5).

No significant difference appears between executives and blue collar workers concerning the impact of temperature in July: both choose larger lot sizes where the weather in July is warmer. However, the behavior of executives seems to be more heavily influenced by winter weather than is the behavior of blue collar workers. First, the former choose to locate closer to the city center than the latter when the temperature in January in colder. Second, the executives locate closer to the city center when the number of rainy days increases, whereas blue collar workers are not responsive to this climate variable.

Various mechanisms may explain this pattern of behavior, but further investigations are needed to rigorously identify them. Nevertheless, we will mention an initial interpretation. As noted by Wheaton (1974), "With an in- come inelastic land demand and noticeably greater commuting costs for the wealthy, greater income leads to more central locations. If land demands are income elastic and commuting expenses are relatively fixed, income should increase with distance from work" (p. 620-21). Indeed, this pattern of location behavior has been shown to occur in France (Brueckner, Thisse, and Zenou 1999). If harsher winter climates correspond with increased transportation costs, we might expect higher-earning households to choose more central locations in such conditions.

\section{Robustness Checks}

As previously noted, distance increases with urban-area population, and lot size decreases. On average, lot size (distance) is $20 \%$ smaller (larger) in urban areas with at least 200,000 inhabitants than in urban areas with less than 200,000 inhabitants. To test if the mechanisms driving preferences for lot size and proximity differ with the size of urban areas, we estimate models using two subsamples defined by population level. Results are presented in Table 6.

Selection mechanisms in the two subsamples behave as in the whole sample, with the exception of the inverse Mills ratio in small urban areas (which controls for the fact that we select households that choose to live in a house vs. an apartment), which is (weakly) significant. In the small urban areas, lot size appears to be driven less by market constraints than by household preferences. While wealthier households do locate on larger lots in both subsamples, the influences of other household characteristics become significant in the subsample restricted to small urban areas, with larger families locating on larger lots. The effect of distance on lot size behaves in the same 
TABLE 6

Structural Equation Estimates for Small and Large Urban Areas

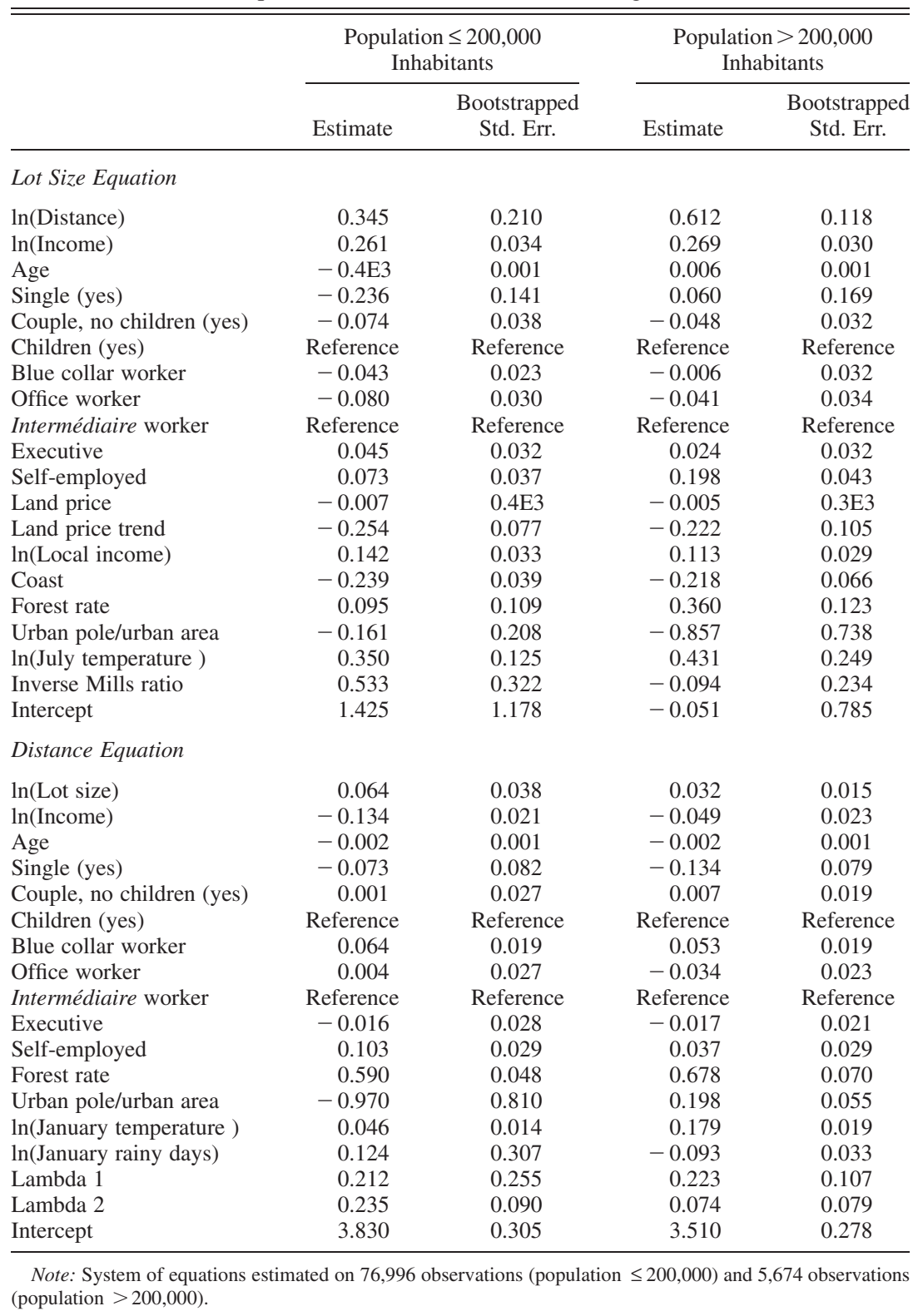

way, with a larger magnitude in the subsample restricted to large urban areas.

Regarding the climate variables, July temperature behaves in the same way in both subsamples, but we find some differences in the effect of winter climate. The distance to the city center increases with the temperature in
January in both subsamples, but at a lower rate in the smaller urban areas. Moreover, the distance to the city center decreases with the number of days of precipitation in January in large urban areas. These last two results are consistent with the notion that commuting conditions are of greater concern to house- 
holds in a large metropolis than to those in a smaller city.

\section{CONCLUSION}

The process of urban sprawl and its primary determinants, falling transportation costs and rising incomes, have been well identified by urban economists' theoretical models and their empirical extensions. The trade-off central to households' residential decisions is that between the cost of accessibility and the cost of residential land. We consider how climate may affect this trade-off. In particular, we hypothesize that in warmer climates, commuting costs are lower because the journey is faster and less hazardous, and that the preference for outdoor lifestyles is stronger. Consequently, households tend to locate farther from urban centers and on larger plots of land where climate is warmer. We use householdlevel data from French housing surveys to model a household's simultaneous choice of accessibility and lot size. In this way, we model a household's sprawling residential behavior rather than the sprawl at the level of an urban area. This approach is consistent with traditional definitions of sprawl (accessibility, residential density), but it stands in contrast to previous empirical analyses of urban sprawl, which utilize urban-area level measures of sprawl.

The empirical results have well-behaved control variables that are consistent with expectations derived from urban economics analyses. The significance of variables controlling for climate in both the distance and lot size equations suggests that climate does influence a household's residential preferences, and that the degree to which the urban structure itself is more or less sprawling also depends on climate. In particular, we find that households occupy larger lots in warmer sum- mer climates and locate farther from urban centers in milder winter climates. We also find evidence that the behavioral effects of climate vary with household characteristics. We look at one type of characteristic (socioprofessional status), finding that households of executive status are more sensitive than blue collar workers to the influence of climate on accessibility. The exploration of other factors is potentially fertile ground for future work.

As societies face ongoing environmental and social challenges posed by climate change and urban sprawl, it is important to improve our understanding of the relationship between these two phenomena. The contribution of urban sprawl to climate change is well known. Here, we show a reverse relationship between climate and sprawling residential behavior: households' residential preferences are influenced by climate conditions. Our results are obtained in cross-section, but they can be used as a basis for dynamic predictions: ${ }^{16}$ if the French climate warms in the coming decades, regions in the central and northern regions of the country, where the current climate is quite cold, may experience climates more similar to those currently found in the southern Mediterranean areas. Assuming stability of household preferences, our results predict that global warming will increase households' demand for larger lot sizes farther from urban centers. Put another way, global warming and sprawling residential behavior are likely to reinforce one another. A broader understanding of the link between urban sprawl and global warming will be strengthened by analyses that build on these first empirical findings, which are obtained through analysis of one country.

\footnotetext{
16 Our survey period (1984-2006) does not allow us to test whether households change their expectation about future climate. People have become aware of warming too recently to incorporate it into their location decisions.
} 


\section{APPENDIX}

TABLE A1

Bivariate Probit Results

\begin{tabular}{|c|c|c|}
\hline & Estimate & Std. Err. \\
\hline \multicolumn{3}{|l|}{ House } \\
\hline $\ln ($ Income $)$ & 0.030 & 0.040 \\
\hline Age & 0.009 & 0.002 \\
\hline Marital status (single) & -1.362 & 0.057 \\
\hline Couple, no child (yes) & -0.520 & 0.041 \\
\hline Children & Reference & Reference \\
\hline Blue collar worker & 0.155 & 0.044 \\
\hline Office worker & -0.116 & 0.048 \\
\hline Intermédiaire worker & Reference & Reference \\
\hline Executive & -0.150 & 0.045 \\
\hline Self-employed & 0.057 & 0.054 \\
\hline Land price trend & -0.702 & 0.122 \\
\hline Urban area population $<50,000$ & Reference & Reference \\
\hline Urban area population 50,000 to 100,000 & -0.154 & 0.059 \\
\hline Urban area population 100,000 to 200,000 & -0.201 & 0.060 \\
\hline Urban area population 200,000 to 500,000 & -0.616 & 0.050 \\
\hline Urban area population $>500,000$ & -0.822 & 0.050 \\
\hline Forest rate & 0.550 & 0.099 \\
\hline Coastal community & -0.512 & 0.040 \\
\hline Urban pole/urban area & 0.173 & 0.106 \\
\hline $\ln ($ July temperature $)$ & -2.402 & 0.160 \\
\hline Energy conserving renovations & 0.387 & 0.081 \\
\hline Social help for housing & 0.132 & 0.041 \\
\hline Self-financing & -0.223 & 0.050 \\
\hline \multicolumn{3}{|l|}{ Suburb } \\
\hline $\ln$ (income) & -0.251 & 0.033 \\
\hline Age & -0.011 & 0.001 \\
\hline Marital status (single) & -0.598 & 0.054 \\
\hline Couple, no child (yes) & -0.040 & 0.037 \\
\hline Children (yes) & Reference & Reference \\
\hline Blue collar worker & 0.228 & 0.035 \\
\hline Office worker & -0.048 & 0.041 \\
\hline Intermédiaire worker & Reference & Reference \\
\hline Executive & -0.077 & 0.038 \\
\hline Self-employed & 0.209 & 0.046 \\
\hline Land price & 0.001 & $0.4 \mathrm{E} 3$ \\
\hline Land price trend & -0.191 & 0.109 \\
\hline Urban area population $<50,000$ & Reference & Reference \\
\hline Urban area population 50,000 to 100,000 & 0.259 & 0.040 \\
\hline Urban area population 100,000 to 200,000 & 0.389 & 0.042 \\
\hline Urban area population 200,000 to 500,000 & 0.305 & 0.039 \\
\hline Urban area population $>500,000$ & 0.539 & 0.043 \\
\hline Forest rate & 1.816 & 0.095 \\
\hline $\ln ($ Local income $)$ & 0.193 & 0.029 \\
\hline Coastal community & -0.704 & 0.038 \\
\hline Urban pole/urban area & 0.515 & 0.100 \\
\hline $\ln ($ July temperature $)$ & -1.934 & 0.257 \\
\hline $\ln ($ January temperature $)$ & -0.083 & 0.030 \\
\hline $\ln ($ January rainy days) & -0.137 & 0.089 \\
\hline Rho & 0.652 & 0.015 \\
\hline
\end{tabular}

Note: Bivariate probit model estimated on 16,943 observations. 


\section{Acknowledgments}

For this research, Grout was a postdoctoral researcher at INRA, CESAER, in Dijon, France, with the financial support of the Conseil Régional de Bourgogne.

\section{References}

Anas, Alex, Richard Arnott, and Kenneth A. Small. 1998. "Urban Spatial Structure." Journal of Economic Literature 36 (3): 1426-64.

Bart, István László. 2010. "Urban Sprawl and Climate Change: A Statistical Exploration of Cause and Effect, with Policy Options for the EU." Land Use Policy 27 (2): 283-92.

_. 2000. "Urban Sprawl: Diagnosis and Remedies." International Regional Science Review 23 (2): 160-71.

2001. "Urban Sprawl: Lessons from Urban Economics." Brookings-Wharton Papers on Urban Affairs (1): 65-97.

Brueckner, Jan K., Jacques-François Thisse, and Yves Zenou. 1999. "Why Is Central Paris Rich and Downtown Detroit Poor? An Amenity-Based Theory." European Economic Review 43 (1): 91-107.

Burchfield, Marcy, Henry G. Overman, Diego Puga, and Matthew A. Turner. 2006. "Causes of Sprawl: A Portrait from Space." Quarterly Journal of Economics 121 (2): 587-634.

Cavailhès, Jean, Daniel Joly, Mohamed Hilal, Thierry Brossard, and Pierre Wavresky. 2014. "Économie urbaine et comportement du consommateur face au climat." Revue Économique 65 (4): 591-619.

Cheshire, Paul C., and Stefano Magrini. 2006. "Population Growth in European Cities: Weather Matters-But Only Nationally." Regional Studies 40 (1): 23-37.

Conseil Général de l'Environnement et du développement durable (CGEDD). 2015. Le prix de l'immobilier d'habitation sur le long terme. La défense, France: CGEDD.

European Commission. 2006. Urban Sprawl in Europe: The Ignored Challenge. Copenhagen: Directorate General Joint Research Center.

European Environment Agency. 1995. CORINE Land Cover Database. Copenhagen: EEA.

Galster, George, Royce Hanson, Michael R. Ratcliffe, Harold Wolman, Stephen Coleman, and Jason Freihage. 2001. "Wrestling Sprawl to the Ground: Defining and Measuring an Elusive Concept." Housing Policy Debate 12 (4): 681-717.

Glaeser, Edward L., and Matthew Kahn. 2004. "Sprawl and Urban Growth." In Handbook of Regional and Urban Economics, Vol. 4, ed. E. S. Mills, 2481-527. Amsterdam: North-Holland, Elsevier.
Glaeser, Edward L., Matthew Kahn, and Chenghuan Chu. 2001. Job Sprawl: Employment Location in U.S. Metropolitan Areas. Washington, DC: Brookings Institution, Center on Urban and Metropolitan Policy.

Gouriéroux, Christian. 2000. Econometrics of Qualitative Dependent Variables. Cambridge: Cambridge University Press.

Graves, Philip E. 1976. "A Reexamination of Migration, Economic Opportunity, and the Quality of Life." Journal of Regional Science 16 (1): 10712.

1980. "Migration and Climate." Journal of Regional Science 20 (2): 227-37.

Graves, Philip E., and Peter D. Linneman. 1979. "Household Migration: Theoretical and Empirical Results." Journal of Urban Economics 6 (3): 383404.

Ham, John C. 1982. "Estimation of a Labour Supply Model with Censoring Due to Unemployment and Underemployment." Review of Economic Studies 49 (3): 335-54.

Hilal, Mohamed. 2010. "Odomatrix. Calcul de distances routières intercommunales." Cahier des Texhniques de l'INRA. 2010 (1): 41-63.

INSEE. 1988. Enquête Logement en 1988. Paris: Direction des statistiques démographiques et sociales (DSDS).

1992. Enquête Logement en 1992. Paris: Direction des statistiques démographiques et sociales (DSDS).

- 1996. Enquête Logement en 1996. Paris: Direction des statistiques démographiques et sociales (DSDS).

—. 2002. Enquête Logement en 2002. Paris: Direction des statistiques démographiques et sociales (DSDS).

- 2006a. Enquête Logement en 2006. Paris: Direction des statistiques démographiques et sociales (DSDS).

- 2015. Statistiques de prix et indices notaires de France. Paris: INSEE.

Intergovernmental Panel on Climat Change (IPCC). 2014. Climate Change 2014: Impacts, Adaptation and Vulnerability, Vol. 1, Global and Sectoral Aspects, Chap 8: Urban Areas. Geneva: IPCC, WGII ARS. Available at www.ipcc.ch/report/ar5/.

Irwin, Elena G., Kathleen P. Bell, Nancy E. Bockstael, David A. Newburn, Mark D. Partridge, and JunJie Wu. 2009. "The Economics of Urban-Rural Space." Annual Review of Resource Economics 1: 435-59.

Irwin, Elena G., P. Wilner Jeanty, and Mark D. Partridge. 2014. "Amenity Values versus Land Constraints: The Spatial Effects of Natural Landscape Features on Housing Values." Land Economics 90 (1): 61-78. 
Joly, Daniel, Thierry Brossard, Hervé Cardot, Jean Cavailhès, Mohaned Hilal, and Pierre Wavresky. 2011. "Temperature Interpolation Based on Local Information: The Example of France." International Journal of Climatology 31 (14): 2141-53.

Kasanko, Marjo, José I. Barredo, Carlo Lavalle, Niall McCormick, Luca Demicheli, Valentina Sagris, and Arne Brezger. 2006. "Are European Cities Becoming Dispersed? A Comparative Analysis of 15 European Urban Areas." Landscape and Urban Planning 77 (1-2): 111-30.

Lacroix, Anne, and Alban Thomas. 2011. "Estimating the Environmental Impact of Land and Production Decisions with Multiple Selection Rules and Panel Data." American Journal of Agricultural Economics 93 (3): 784-802.

Lecat, Gabriel. 2006. "Analyse économique de la planification urbaine" [Urban Land Planning Economics]. Ph.D. dissertation. University of Burgundy and INRA.

Mieszkowski, Peter, and Edwin S. Mills. 1993. "The Causes of Metropolitan Suburbanization.” Journal of Economic Perspectives 7 (3): 135-47.

Nechyba, Thomas J., and Randall P. Walsh. 2004. "Urban Sprawl." Journal of Economic Perspectives 18 (4): 177-200.

Newman, Peter, and Jeffrey Kenworthy. 1999. Sustainability and Cities: Overcoming Automobile Dependence. Washington, DC: Island Press.
Patacchini, Eleonora, and Yves Zenou. 2009. "Urban Sprawl in Europe." Brookings-Wharton Papers on Urban Affairs 25 (2): 125-49.

Roback, Jennifer. 1982. "Wages, Rents, and the Quality of Life." Journal of Political Economy 90 (6): 1257-78.

Roe, Brian, Elena G. Irwin, Hazel A. Morrow-Jones. 2004. "The Effects of Farmland, Farmland Preservation, and Other Neighborhood Amenities on Housing Values and Residential Growth." Land Economics 80 (1): 55-75.

Smith, Lawrence B., Kenneth T. Rosen, and George Fallis. 1988. "Recent Developments in Economic Models of Housing Markets." Journal of Economic Literature 26 (1): 29-64.

Wheaton, William C. 1974. "A Comparative Static Analysis of Urban Spatial Structure." Journal of Economic Theory 9 (2): 223-37.

Wu, JunJie. 2006. "Environmental Amenities, Urban Sprawl, and Community Characteristics." Journal of Environmental Economics and Management 52 (2): 527-47.

Yen, Steven T., Biing-Hwan Lin, and David M. Smallwood. 2003. "Quasi- and Simulated Likelihood Approaches to Censored Demand Systems: Food Consumption by Food Stamp Recipients in the United States." American Journal of Agricultural Economics 85 (2): 458-78. 